\title{
Intrauterine Contraceptive Device Insertion during Cesarean Section versus Conventional Application: A Randomized Clinical Trial
}

Sara A Salem, Hamada AA Ali, Maha A Katta, Nesreen AA Shehata*, Mohamed AM Eweis and Gaber K Hussein

Department of Obstetrics and Gynecology, Beni Suef University, Beni Suef City, Egypt

*Corresponding author: Nesreen AA Shehata, Department of Obstetrics and Gynecology, Beni Suef University, Beni Suef City, Egypt; E-mail: nesoomar@yahoo.com

Received date: October 25, 2018; Accepted date: November 15, 2018; Published date: November 19, 2018

Copyright: $@ 2018$ Salem SA, et al. This is an open-access article distributed under the terms of the Creative Commons Attribution License, which permits unrestricted use, distribution, and reproduction in any medium, provided the original author and source are credited.

\section{Abstract}

Objective: To compare immediate intrauterine contraceptive device (IUCD) (Copper T 380A) insertion (within 10 minutes of placenta delivery) after caesarean section versus conventional application.

Method: The study involved 200 women who were booked for elective cesarean section and wanted IUCD insertion in Department of obstetrics and gynecology, Beni Suef University Hospital, Egypt. Participants were randomly assigned for IUCD insertion at the time of cesarean delivery or 6 weeks postpartum. The primary outcome was IUCD expulsion rate.

Results: Follow-up of women within 6 months of IUCD application showed that expulsion rate was 10/94 (10.6\%) in immediate group but $4 / 95(4.2 \%)$ in conventional group with no statistical significance between the studied groups. Pelvic infection rate was $2.3 \%$ and $2.2 \%$ respectively, a difference that was not statistically significant. Also there was no significant difference in bleeding patterns along the 6 weeks follow up. Continuation rate was 75/94 $(83 \%)$ in immediate group and 83/95 (87.4\%) in conventional group. Device tail visibility at 1 week, 6 weeks and 6 months postpartum was significantly lower in immediate group than conventional group ( $p$ value $<0.0001$ ).

Conclusion: Insertion of Copper T 380A IUD during C-section is safe and effective with expected low expulsion, and high continuation rate as in conventional method.

Clinical trial registry: clinicaltrials.gov NCT02674139.

Synopsis: Insertion of Copper T 380A during C-section is safe and effective with expected low expulsion, high satisfaction and continuation rates. It should be offered to mothers planned for elective cesarean.

Keywords: Contraception; IUD; Immediate postpartum; LARC; Family planning

\section{Introduction}

Post-partum period is very critical time for both woman and newborn that needs a special health care. Morbidity and mortality rates are quite high during this period [1]. Also it is important to provide highly effective contraception immediately after delivery especially in communities where women have limited access to medical service [2]. Effective contraception after delivery helps preventing unintended pregnancies and their risk of major maternal complications including third-trimester bleeding and anemia [3]. In a survey of postpartum women, $23 \%$ confirmed that they would have chosen an immediate intra uterine contraceptive device (IUCD) insertion after delivery if it had been available [4]. Immediate post placental intra-caesarean IUD insertion offers a reversible and effective, long term contraception, which does not interfere with breast feeding [5]. It may also avoid the discomfort related to standard insertion and bleeding from insertion will be disguised by lochia. The woman is known to be not pregnant, and her motivation for contraception will be high [6]. Most recent studies showed wide variability in reported expulsion rates, ranging from $2 \%$ to $27 \%$ after vaginal delivery and $0 \%$ to $20 \%$ after cesarean [7-10]. Counseling women is difficult when evidence from randomized controlled trials is limited. The benefit of highly effective contraception immediately after delivery may outweigh the disadvantage of increased risk of expulsion. Clinical follow-up is important in detecting early expulsion [11]. Thus, our trial was designed to compare rates of Copper T380A IUCD complications with immediate versus delayed IUCD insertion after cesarean delivery.

\section{Materials and Methods}

This controlled randomized clinical trial (RCT) was conducted at the Department of Obstetrics and Gynecology, Beni Suef University Hospital from February 2016 till February 2018.

After ethical committee approval, women started to be recruited. Informed consent was obtained from all individual participants included in the study during the last antenatal care visit. Study population included pregnant full term women who were scheduled for an elective cesarean delivery. They were counseled about different contraceptive options. If they asked for insertion of Copper T380A IUCD (PARAGARD T380A ${ }^{\circ}$ the cooper company, USA), they were asked to join the study.

Exclusion criteria included allergy to copper, ante- or intra-partum hemorrhage, hemorrhagic disorders, pelvic tuberculosis or current 
Citation: Salem SA, Ali HAA, Katta MA, Shehata NAA, Eweis MAM, et al. (2018) Intrauterine Contraceptive Device Insertion during Cesarean Section versus Conventional Application: A Randomized Clinical Trial. Clinics Mother Child Health 15: 309. doi: $10.4172 / 2090-7214.1000309$

Page 2 of 5

pelvic inflammatory disease, ruptured membranes for more than $24 \mathrm{~h}$ prior to delivery, history of chorioamnionitis, Known uterine abnormalities e.g., bicornuate uterus, uterine myoma, multiple pregnancies, history of ectopic pregnancy, diagnosis of active cervical infection at time of insertion.

An informed consent was taken after explaining the study objective and the procedures to potential participants. Participation was voluntary and we informed the participants that the decision would not affect the quality of care they receive.

The study consisted of 200 women who were assigned randomly in a 1:1 ratio into 2 groups to either immediate insertion (intra cesarean insertion) (immediate group) or delayed insertion (6 weeks postpartum) (conventional group) using computer generated random numeric table. The random allocation sequence was concealed in sealed opaque envelopes that were opened after delivery of the placenta. The overall rate of missed follow-up was low 11/200 (5.5\%) and not significantly different between two groups, immediate $[6 / 100$ $(6 \%)$ ] vs. conventional method [5/100 (5\%), $\mathrm{p}=0.76]$. An overview of the trial is shown in CONSORT diagram (Figure1).

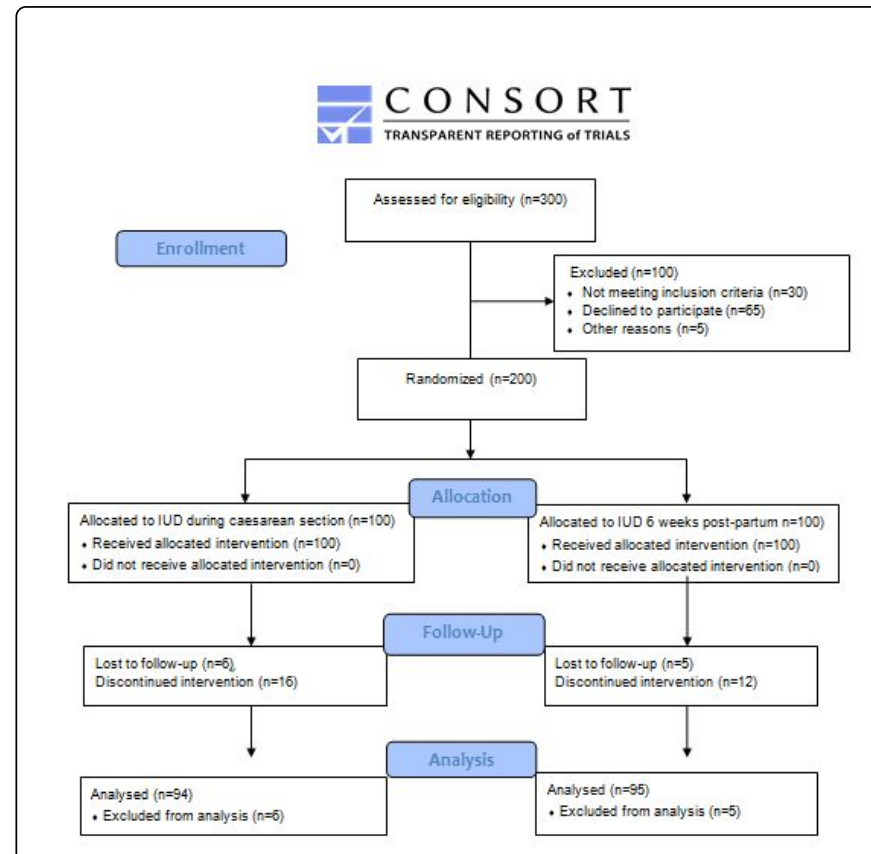

Figure 1: CONSORT 2010 flow diagram.

Uterine cavity was inspected for presence of malformations, which would be contraindication for use of IUCD. The IUCD was removed from the insertion sleeve and was placed on the sterile field. Uterus was stabilized by grasping it at fundus. Insertion was done after delivery of placenta, (IUCD was held between middle and index finger). It was placed into the uterus through uterine incision and was left at fundus of uterus. Strings were directed towards the lower uterine segment without disturbing IUCD's position. The surgeon took good care not to include IUCD strings within the sutures. Conventional application IUCD was inserted in aseptic media as described in the manufacturer's instructions at the 6-week postpartum visit. Women in conventional group were screened for pregnancy with a urine pregnancy test. IUCDs were provided by the Drammen Kommunale Trikk (DKT) international organization for family planning, Egypt office. They were provided free of charge.

Before discharge, each woman was given a card, showing type and date of insertion. Women were informed about the IUCD side effects. Women were scheduled for a follow-up examination at 1 week, 6 weeks and 6 months after the insertion. They were advised to contact the staff immediately if they experienced unusual vaginal discharge different from the usual lochia, lower abdominal pain, especially if accompanied by fever or chills and history of missed IUCD.

The patient was followed up by vaginal ultrasound in 3 visits and when she gave a history of not feeling the threads. However, the most dependable way of follow up was the history and clinical examination and taking into consideration cost of ultrasonography.

At each visit the patient was questioned for any symptoms of complications or side effects. In addition, a pelvic examination (per speculum) and trans-vaginal ultrasound were performed. If speculum examination showed long IUCD threads, they were cut $2 \mathrm{~cm}$ at level of external os. If they were not seen, pelvic ultrasonography was done to confirm in situ IUCD.

IUCD expulsion was verified clinically and by transvaginal ultrasound examination with a TUS-Xario200 diagnostic ultrasonography system (Toshiba America Medical Systems, Tustin, CA, USA), which was equipped with a $5 \mathrm{MHz}$ transvaginal probe. In case of expulsion the patient was offered IUCD replacement at time of examination and ultrasonography was repeated. Decision was left to the clinician and patient preference. Vaginal bleeding in the first menstruation after insertion was assessed by asking participants about number of pads per day, presence of blood clots and duration of puerperum. Uterine perforation was confirmed by pelvic ultrasound or $\mathrm{X}$-ray pelvis. Pelvic infection was associated with fever, rigors, lower abdominal pain, lower abdominal tenderness and offensive vaginal discharge. Quantification of pelvic pain and severity grading were evaluated using visual analogue scale (VAS). The VAS was drawn as a $10 \mathrm{~cm}$ line explaining woman's opinion of the degree of pain. One side of the line represented "unbearable pain", and the other side represented "no pain at all". Women were asked to rate the degree of pain by making a mark on the line. The scores received from the scale were classified into mild pain if it was between 1 and 3 points moderate between 4 and 7 points, and severe between 8 and 10 points [12].

Pregnancy (IUCD failure) was detected by serum pregnancy test and pelvic ultrasound in suspicious cases (missed period-misplaced IUD-expelled IUCD either partial or complete).The IUCD was removed in the case of partial expulsion, bleeding or pain, or at the patient's request.

Power analysis of a chi-square test for IUCD expulsion rate (primary outcome) was conducted in $\mathrm{G}^{*}$ Power Version 3.1.9.2 (computer software) to determine a sufficient sample size using an alpha error of probability of 0.05 , power of 0.95 , a medium effect size $(\mathrm{w}=0.3)$ and 1 degree of freedom. Based on the aforementioned assumptions, the desired sample size is 145 . By calculating $25 \%$ drop out, so the least total sample size in both groups was 200 patients.

Data were statistically described in terms of mean \pm standard deviation ( \pm SD), frequencies (number of cases) and relative frequencies (percentages) when appropriate. The normal distribution of continuous variables of the demographic data was evaluated with the use of the Kolmogrov-Smirnov test. Comparison of numerical 
Citation: Salem SA, Ali HAA, Katta MA, Shehata NAA, Eweis MAM, et al. (2018) Intrauterine Contraceptive Device Insertion during Cesarean Section versus Conventional Application: A Randomized Clinical Trial. Clinics Mother Child Health 15: 309. doi: $10.4172 / 2090-7214.1000309$

Page 3 of 5

variables between the study groups was analyzed with the independent samples t-test (when the data showed normal distribution) and using Mann-Whitney $U$ test for data which was not normally distributed. For comparing categorical data e.g. expulsion rates Chi square $\left(\chi^{2}\right)$ test was performed, and for small sample sizes, Fisher's exact test was used as appropriate. Statistical significance was set at a probability value $(\mathrm{P}$ value $\leq 0.05$ ). The Statistics Package for Social Science (Version 22; SPSS Inc.) was used for all statistical analyses.

\section{Results}

Baseline characteristics of study population are shown in Table 1. After randomization, both groups were similar for demographic and clinical data. There was no statistical significant difference between the studied groups.

\begin{tabular}{|c|c|c|c|}
\hline & $\begin{array}{l}\text { Immediate } \\
(n=94)\end{array}$ & $\begin{array}{l}\text { Conventional } \\
\text { group }(n=95)\end{array}$ & $\begin{array}{l}\mathrm{P} \text { - } \\
\text { value }\end{array}$ \\
\hline Age (years) & $29.8(5 \%)$ & $29.3(5 \%)$ & 1 \\
\hline Gravidity & $2.7(1 \%)$ & $2.5(1 \%)$ & 1 \\
\hline Parity & $2.5(1 \%)$ & $2.3(1 \%)$ & 1 \\
\hline \multirow[t]{2}{*}{ Education } & Literate 73 (78\%) & Literate $71(74 \%)$ & 0.520 \\
\hline & Illiterate $21(22 \%)$ & Illiterate $24(25 \%)$ & 0.627 \\
\hline \multirow[t]{3}{*}{ Employment } & $\begin{array}{l}\text { Unemployed } \\
(71 \%)\end{array}$ & $\begin{array}{l}\text { Unemployed } \\
(76 \%)\end{array}$ & 0.437 \\
\hline & $\begin{array}{l}\text { Self-employed } 14 \\
(15 \%)\end{array}$ & $\begin{array}{l}\text { Self-employed } 5 \\
(5 \%)\end{array}$ & 0.022 \\
\hline & $\begin{array}{l}\text { Salaried job } 13 \\
(14 \%)\end{array}$ & $\begin{array}{l}\text { Salaried job } 18 \\
(19 \%)\end{array}$ & 0.355 \\
\hline $\begin{array}{l}\text { No. of previous C- } \\
\text { sections }\end{array}$ & $2.4(1 \%)$ & $2.4(1 \%)$ & 1 \\
\hline Last child birth & $3.4(1 \%)$ & $3.2(1 \%)$ & 1 \\
\hline \multirow{4}{*}{$\begin{array}{l}\text { Future pregnancy } \\
\text { desire }\end{array}$} & $1-2$ years $0(0 \%)$ & $1-2$ years $1(1 \%)$ & 0 \\
\hline & $3-5$ years $2(2 \%)$ & $3-5$ years $5(5 \%)$ & 0.263 \\
\hline & $\begin{array}{l}\text { More than } 5 \text { years } \\
36(38 \%)\end{array}$ & $\begin{array}{l}\text { More than } 5 \text { years } \\
39(41 \%)\end{array}$ & 0.674 \\
\hline & Not sure $56(60 \%)$ & Not sure $50(53 \%)$ & 0.333 \\
\hline
\end{tabular}

Data is expressed in number (\%)

Table 1: Baseline characteristics in study population.

During follow-up visits at 1 week, 6 weeks and 6 months after IUCD insertion, expulsion rate was $3.2 \%, 3.3 \%$ and $4.5 \%$, respectively in immediate group. Conventional group showed expulsion rate of $0 \%$, $1.1 \%$ and $3.3 \%$, respectively. Expulsion rate was not significantly different between both groups (Tables 2-4).

\begin{tabular}{|l|l|l|l|}
\hline $\begin{array}{l}\text { Complications after } \\
\text { week of insertion }\end{array}$ & $\begin{array}{l}\text { Immediate } \\
\text { group } \\
\mathbf{( n = 9 4 )}\end{array}$ & $\begin{array}{l}\text { Conventional } \\
\text { group } \\
(\mathbf{n}=95)\end{array}$ & P-value \\
\hline Expulsion rate & $3(3 \%)$ & $0(0 \%)$ & 0 \\
\hline Vaginal bleeding & $5(5 \%)$ & $2(2 \%)$ & 0.262 \\
\hline Strings Visibility & $7(7 \%)$ & $92(97 \%)$ & $<0.0001^{*}$ \\
\hline \multicolumn{2}{|l|}{ Data is expressed in number (\%), P-value $(<0.05)$ is statistically significant } \\
\hline
\end{tabular}

Table 2: Complications of intrauterine contraceptive device after 1 week of insertion in studied groups.

Heavy vaginal bleeding rate (Table 3) was reported within 1 week, 6 weeks and 6 months after IUCD insertion (5.3\%, 5.4\% and 19.3\% respectively) in immediate group patients and $(2.1 \%, 8.5 \%$ and $21.8 \%$ respectively) in conventional group. Tables 2-4 showed no significant difference between both groups. Perforation was not reported in any case.

\begin{tabular}{|l|l|l|l|}
\hline $\begin{array}{l}\text { Complications after } \\
\text { weeks of insertion }\end{array}$ & $\begin{array}{l}\text { Immediate } \\
\text { group } \\
(\mathbf{n}=94)\end{array}$ & $\begin{array}{l}\text { Conventional } \\
\text { group } \\
(\mathbf{n}=95)\end{array}$ & P-value \\
\hline Expulsion rate & $3(3 \%)$ & $1(1 \%)$ & 0.326 \\
\hline Vaginal bleeding & $5(5 \%)$ & $8(9 \%)$ & 0.282 \\
\hline Strings visibility & $16(18 \%)$ & $89(95 \%)$ & $<0.0001^{*}$ \\
\hline \multicolumn{2}{|l|}{ Data is expressed in number (\%), P-value $(<0.05)$ is statistically significant } \\
\hline
\end{tabular}

Table 3: Complications of intrauterine contraceptive device after 6 weeks of insertion in studied groups.

Pelvic infection rate in immediate group was $2(2.3 \%)$ and $2(2.2 \%)$ in conventional group. No significant difference is shown in Table 4.

\begin{tabular}{|l|l|l|l|}
\hline $\begin{array}{l}\text { Complications after } \mathbf{6} \text { months of } \\
\text { insertion }\end{array}$ & Immediate group (n=94) & Conventional group (n=95) \\
\hline Expulsion rate & $4(5 \%)$ & $3(3 \%)$ & 0.483 \\
\hline Vaginal bleeding & $17(19 \%)$ & $20(22 \%)$ & 0.610 \\
\hline Strings visibility & $22(25 \%)$ & $79(86 \%)$ & $2(2 \%)$ \\
\hline Pelvic infection & $2(2 \%)$ & 1 \\
\hline Data is expressed in number $(\%)$, P-value $(<0.05)$ is statistically significant & \\
\hline
\end{tabular}

Table 4: Complications of intra uterine contraceptive device after 6 months of insertion in studied groups. 
Citation: Salem SA, Ali HAA, Katta MA, Shehata NAA, Eweis MAM, et al. (2018) Intrauterine Contraceptive Device Insertion during Cesarean Section versus Conventional Application: A Randomized Clinical Trial. Clinics Mother Child Health 15: 309. doi: $10.4172 / 2090-7214.1000309$

Page 4 of 5

Strings visibility was significantly different between both groups ( $\mathrm{P}$ $\leq 0.005$ ) (Tables 2-4). Rate of visible strings in immediate group was 7 (7.4\%) after 1 week, 19 (17.6\%) after 6 weeks and 22 (25\%) after 6 months follow up. In conventional group the rate was 92 (96.8\%) after 1 week, 89 (94.7\%) after 6 weeks and 7 (85.9\%) after 6 months follow up (Tables 2-4).

There was only one case of pregnancy reported in conventional group.
There was no significant difference in cumulative removal rate within 6 months (16/94 women (17\%) vs. 12/95 women (12.6\%) in immediate group and conventional group, respectively (P value $=0.396$ ). IUCD was removed in 28 cases. Sixteen of them were switched to combined oral contraceptive pills. Ten were switched to medroxy progesterone acetate injection and two stopped contraception (Table 5).

\begin{tabular}{|l|l|l|l|}
\hline Discontinuation & Immediate group (n=94) & Conventional group (n=95) & P-value \\
\hline Expulsion & $10(11 \%)$ & $4(4 \%)$ & 0.068 \\
\hline Pain & $0(0 \%)$ & $1(1 \%)$ & 0 \\
\hline Bleeding & $3(3 \%)$ & $4(4 \%)$ & 0.709 \\
\hline Pelvic Infection & $1(1 \%)$ & $2(2 \%)$ & 0.573 \\
\hline Psychological & $1(1 \%)$ & $0(0 \%)$ & 0 \\
\hline Pregnancy & $0(0 \%)$ & $1(1 \%)$ & 0 \\
\hline Baby died & $1(1 \%)$ & $0(0 \%)$ & 0 \\
\hline Data is expressed in number, $p$-value $(<0.05)$ is statistically significant ${ }^{*}$ & & \\
\hline
\end{tabular}

Table 5: Comparison between both groups regarding different causes of discontinuation or removal of IUCD.

\section{Discussion}

Our randomized clinical trial showed higher expulsion rate in women having IUCD during cesarean section. Similarly, Levi et al. randomized 112 women to intra cesarean insertion of either a CuT380A or 52-mg LNG-IUD vs. insertion 6 weeks or more postpartum. Expulsion rate after intra cesarean insertion was $8 \%$ compared with $2 \%$ in the delayed-insertion group, but the difference did not reach statistical significance [9]. Another small $(n=68)$ RCT conducted in Uganda found no difference in the number of expulsions between intra cesarean and delayed CuT380A insertions (one expulsion in each group) [13]. Other studies reported high expulsion rate in immediate group of IUD insertion $[14,15]$. Immediate IUD insertion within cesarean section offers convenience, assurance that the patient is not pregnant and insurance coverage that may last only through the pregnancy and postpartum period. In a survey of postpartum women, $23 \%$ stated that they would have chosen an immediate insertion of IUD if it had been available [4]. Studies that have investigated return for IUD insertion after delivery have consistently found low rates of insertion for women who desired an IUD (27-60\%) [16-17]. However, there is wide variability of expulsion rates across studies suggesting that there are factors that could reduce expulsion rate. Further research will be needed to identify these variables [11]. Thus, this may present clinical difficulties making the patient changes her mind about having it. Strings visibility is an indicator of IUCD position. It also facilitates its removal. The most common complication occurred in our study population was non visibility of strings. This complication was significantly higher in immediate group (intra-cesarean insertion) than conventional group. Patients needed a vaginal ultrasound done to confirm that IUCD was in situ. Studies have reported low visibility of strings following intracesarean insertions of CuT380A IUD $[2,13,18]$. Women undergoing intra cesarean IUCD insertion should be counseled that ultrasound may be required to confirm the location of IUD which adds to clinical difficulties making patients change their mind and choose the conventional method. Moreover, determining if immediate IUD insertion is a reasonable approach may be an individual situation, various factors must be considered, including availability of replacement IUDs after expulsion and the patient population return rate for the postpartum visit [11]. Again this may add to clinical difficulties making patients change their mind about intra cesarean IUD insertion.

In our study, the risk of pelvic infection after intra-cesarean insertion was low and showed no significant difference between both groups. These results were consistent with randomized trials which did not show a difference in infection based on insertion timing [8,9].

There was no significant difference in heavy vaginal bleeding over 1week, 6weeks and 6 months after IUCD insertion. However, a confounding factor that may have been thought to affect vaginal bleeding was the six months follow-up being six weeks later in conventional group than the immediate group.

Strengths of our study are the large sample size compared with most of previous RCTs done and the high follow-up rate, largely achieved by professional study staff getting accurate contact information. The weakness of the study was not looking for the factors that contribute to expulsion rate e.g., provider experience, IUD type, technique of insertion that could be modified and may help to minimize expulsion in clinical practice. Moreover, the study was difficult to be blinded.

Insertion of Copper T 380A IUD during C-section is safe and effective with expected low expulsion, high continuation rates as in conventional group. It is also convenient due to easy painless insertion and no delay in using contraceptive method. Intra-cesarean IUD placement should be offered to eligible mothers planned for elective cesarean section. Other research on wider scale is needed to isolate the modifiable factors that contribute to expulsion e.g., provider experience or IUCD type. This may serve to decrease expulsion in 
Citation: Salem SA, Ali HAA, Katta MA, Shehata NAA, Eweis MAM, et al. (2018) Intrauterine Contraceptive Device Insertion during Cesarean Section versus Conventional Application: A Randomized Clinical Trial. Clinics Mother Child Health 15: 309. doi: $10.4172 / 2090-7214.1000309$

Page 5 of 5

clinical practice. IUCDs with longer strings or modifications to the Copper T380A should be considered to maximize the chances of easy removal when desired.

\section{Conflict of Interest}

Authors declare that there is no conflict of interest.

\section{Funding}

Work is self-funded.

\section{Author Contributions}

All authors of that work contributed in conceptualization the idea, writing manuscript, interpretation of results and writing the discussion.

\section{References}

1. Kumar M, Kumar M, Aggarwal P, Gangania A, Dewan R (2017) A study to evaluate and compare the expulsion and continuation rates of post placental insertion of $\mathrm{Cu} 375$ and $\mathrm{CuT} 380 \mathrm{~A}$ in Indian women at a premier hospital in New Delhi, India. Int J Reprod Contracept Obstet Gynecol 6: 3992-4000.

2. Lucksom PG, Kanungo BK, Sebastian N, Mehrotra R, Pradhan D, Upadhya R (2015) Comparative study of interval versus postpartum Cu-T insertion in a central referral hospital of North East India. Int J Reprod Contracept Obstet Gynecol 4: 47-51.

3. WHO (2005) World Health Organization. Report of a WHO Technical Consultation on Birth Spacing, Geneva.

4. Glazer AB, Wolf A, Gorby N (2011) Postpartum contraception: needs vs. reality. Contracept 83: 238-241.

5. Singal S, Rekha B, Rupali D, Divya, Anjali D, et al. (2014) Clinical Outcome of Postplacental Copper T 380A Insertion in Women Delivering by Caesarean Section. J Clin Diag Res 8: OC01-OC04.

6. Teal SB (2014) Postpartum contraception: optimizing inter-pregnancy intervals. Contracept 89: 487-488.
7. Chen BA, Reeves MF, Hayes JL, Hohmann HL, Perriera LK, et al. (2010) Postplacental or delayed insertion of the levonorgestrel intrauterine device after vaginal delivery: a randomized controlled trial. Obstet Gynecol 116: 1079-1087.

8. Whitaker AK, Endres LK, Mistretta SQ, Gilliam ML (2014) Postplacental insertion of the levonorgestrel intrauterine device after cesarean delivery vs. delayed insertion: a randomized controlled trial. Contracept 89: 534 539 .

9. Levi EE, Stuart GS, Zerden ML, Garrett JM, Bryant AG (2015) Intrauterine Device Placement during Cesarean Delivery and Continued Use 6 Months Postpartum: A Randomized Controlled Trial. Obstet Gynecol 126: 5-11.

10. Dahlke JD, Terpstra ER, Ramseyer AM, Busch JM, Rieg T, et al. (2011) Postpartum insertion of levonorgestrel-intrauterine system at three time periods: a prospective randomized pilot study. Contracept 84: 244-248.

11. Whitaker AK, Chen BA (2018) Society of Family Planning Guidelines: Postplacental insertion of intrauterine devices. Contracept 97: 2-13.

12. Shah S, Makwana K, Shah P (2015) Menstrual characteristics and prevalence of dysmenorrhoea among female physiotherapy students. International J Med Health Res 1: 1-8.

13. Lester F, Kakaire O, Byamugisha J, Averbach S, Fortin J, et al. (2015) Intracesarean insertion of the copper T380A versus 6 weeks postcesarean: a randomized clinical trial. Contracept 91: 198-203.

14. Cohen R, Sheeder J, Arango N, Teal SB, Tocce K (2016) Twelve-month contraceptive continuation and repeat pregnancy among young mothers choosing postdelivery contraceptive implants or postplacental intrauterine devices. Contracept 93: 178-183.

15. Celen S, Sucak A, Yildiz Y, Danişman N (2011) Immediate postplacental insertion of an intrauterine contraceptive device during cesarean section. Contracept 84: 240-243.

16. Ogburn JA, Espey E, Stonehocker J (2005) Barriers to intrauterine device insertion in postpartum women. Contracept 72: 426-429.

17. Bergin A, Tristan S, Terplan M, Gilliam ML, Whitaker AK (2012) A missed opportunity for care: two-visit IUD insertion protocols inhibit placement. Contracept 86: 694-697.

18. Dewan R, Dewan A, Singal S, Bharti R, Kaim M (2016) Non-visualisation of strings after postplacental insertion of Copper-T 380A intrauterine device. J Fam Plan Reprod Health Care 0: 1-9. 